\title{
Effects of relative density and accumulated shear strain on post-liquefaction residual deformation
}

\author{
J. Kim ${ }^{1}$, M. Kazama ${ }^{1}$, and Y. Kwon ${ }^{2}$ \\ ${ }^{1}$ Department of Civil and Environmental Engineering, Tohoku University, Sendai, Japan \\ ${ }^{2}$ Department of Fire and Disaster Prevention, Korea Soongsil Cyber University, Seoul, Korea \\ Correspondence to: Y. Kwon (kyc@mail.kcu.ac) \\ Received: 14 March 2013 - Published in Nat. Hazards Earth Syst. Sci. Discuss.: 24 April 2013 \\ Revised: 13 August 2013 - Accepted: 6 September 2013 - Published: 18 October 2013
}

\begin{abstract}
The damage caused by liquefaction, which occurs following an earthquake, is usually because of settlement and lateral spreading. Generally, the evaluation of liquefaction has been centered on settlement, that is, residual volumetric strain. However, in actual soil, residual shear and residual volumetric deformations occur simultaneously after an earthquake. Therefore, the simultaneous evaluation of the two phenomena and the clarification of their relationship are likely to evaluate post-liquefaction soil behaviors more accurately. Hence, a quantitative evaluation of postliquefaction damage will also be possible. In this study, the effects of relative density and accumulated shear strain on post-liquefaction residual deformations were reviewed through a series of lateral constrained-control hollow cylindrical torsion tests under undrained conditions. In order to identify the relationship between residual shear and residual volumetric strains, this study proposed a new test method that integrates monotonic loading after cyclic loading, and $K_{0^{-}}$ drain after cyclic loading - in other words, the combination of cyclic loading, monotonic loading, and the $K_{0}$ drain. In addition, a control that maintained the lateral constrained condition across all the processes of consolidation, cyclic loading, monotonic loading, and drainage was used to reproduce the anisotropy of in situ ground. This lateral constrain control was performed by controlling the axial strain, based on the assumption that under undrained conditions, axial and lateral strains occur simultaneously, and unless axial strain occurs, lateral strain does not occur. The test results confirmed that the recovery of effective stresses, which occur during monotonic loading and drainage after cyclic loading, respectively, result from mutually different structural restoration characteristics. In addition, in the ranges of $40-60 \%$ relative
\end{abstract}

density and 50-100\% accumulated shear strain, relative density was found to have greater effects than the number of cycles (accumulated shear strain).

\section{Introduction}

In the Niigata earthquake (1964), Alaska earthquake (1964), Hyogoken-nambu earthquake (1995), and Canterbury earthquake (2011), a number of buildings and other infrastructure elements erected on sandy soil were extensively damaged (Kawakami and Asada, 1966; Ishihara, 1993; Hatanaka et al., 1997; Cubrinovski et al., 2011). In particular, the March 2011 Great East Japan Earthquake off the Pacific coast of Tohoku caused widespread damage, including formation of sand boils, the settlement and tilting of buildings, and embankment failures.

Until now, studies have largely focused on identifying whether the phenomenon of liquefaction occurred by judging the soil resistance to cyclic loading (Seed and Idriss, 1971). However, the need for a quantitative projection of the functional deterioration of facilities from the viewpoint of performance design has lately been emphasized. An essential element in the projection is the residual deformation of the ground after earthquakes; however, few studies have investigated post-liquefaction behaviors related to residual deformations.

Residual deformation after liquefaction includes settlement and lateral spreading. In general, during an earthquake, an undrained condition is assumed. Therefore, because residual volumetric strain occurs by draining over a relatively long period of time after the ground motions of the earthquake 
have stopped, the evaluation of settlement requires a lengthy, post-ground motion prediction of volumetric strain. In addition, the evaluation of lateral strain requires the prediction of shear strain, which occurs in undrained conditions (Unno et al., 2006; Unno and Tani, 2008).

The most common damage from volumetric deformation during the post-liquefaction phase is ground settlement. It has also been recognized as the greatest cause of the occurrence of damage associated with liquefaction in previous earthquakes (Ishihara et al., 1996; Tetsuro and Koarai, 2012). In saturated ground, post-liquefaction settlement generally occurs with the dissipation of excess pore water pressure caused by cyclic loading. Therefore, to investigate the liquefaction characteristics of saturated sandy soil, a number of previous studies performed drainage after applying cyclic loading under undrained conditions (Lee and Albaisa, 1974; Yoshimi et al., 1975; Tatsuoka et al., 1984; Nagase and Ishihara, 1988). The existing experimental studies suggest that volumetric strain is influenced by major factors, such as relative density and confining pressure. In addition, many researchers have confirmed that volumetric strain is directly influenced by the stress history during cyclic loading (Nagase and Ishihara, 1988; Kaggawa et al., 1991; Shamoto et al., 1996; Ishihara and Yoshimine, 1992; Pendo et al., 2008; Hatanaka and Yokokji, 2009). Based on these studies, simple evaluation methods have been suggested in order to develop quantitative projections of ground settlement caused by liquefaction (Tokimatsu and Seed, 1987; Ishihara and Yoshimine, 1992; Shamoto et al., 1996). With the recent development of online testing techniques utilizing hollow cylindrical torsion tests, some studies have reported that as the duration of motion in large-magnitude earthquakes is lengthy, accumulated shear strain, an indicator that reflects the number of cycles, is more appropriate as an indicator of shear strain than is maximum shear strain (Sento et al., 2004).

The damage from shear strain includes lateral spreading, which occurs in harbors, riverbanks, and slope failure, which occurs in inclines. Yasuda et al. (1999) performed monotonic loading after cyclic loading to evaluate the shear behaviors that occur during the post-liquefaction phase and confirmed the recovery of effective stress. Other studies found that the residual shear strain is composed of a shear strain component depending on change in effective stress, and a shear strain component independent of effective stress (Shamoto et al., 1997; Wang and Wang, 2012). In previous experimental approaches, most liquefaction tests have considered the characteristics of either residual volumetric strain or residual shear strain. However, few studies have simultaneously evaluated the two variables in a single test to determine a correlation between the two types of deformation. Shamoto et al. (1998) presented, using constitute model which was developed based on the cyclic torsional shear test results and the theory of plasticity, that post-liquefaction shear strain and volumetric strain are not independent of each other. However, quite a few experimental methods that can evaluate the relationship between residual shear strain and residual volumetric strain directly have been provided (Oshima et al., 2008). Takahashi et al. (2012) demonstrated by conducting a lateral constrained online seismic response experiment that even beneath level-ground residual shear strain was generated and accumulated in one direction. Furthermore, no experimental cases using this approach have provided results regarding evaluation methods. In addition, although many studies have pointed to the essential need for the evaluation of stress anisotropy (Kato et al., 2001; Hyodo et al., 2006; Ishihara et al., 1985, 1996), most existing experimental studies have been performed under isotropic stress conditions, and thus do not fully reflect the deformation characteristics that can occur in actual soil conditions. Accordingly, future studies should address these limitations.

Accordingly, the present study was based on two key research objectives. First, this study aimed to propose an integrated test method that evaluates residual deformations that occur during the post-liquefaction phase. A series of lateral constrained hollow cylindrical torsion tests was performed under undrained conditions. Based on the results, the study intended to improve existing test methods that conduct only drainage or monotonic loading after cyclic loading. As a result, this study suggested an integrated test method that includes not only the implementation of monotonic loading after cyclic loading, but also the implementation of drainage until the excess pore water pressure that occurs during the initial process has dissipated. Eventually, by draining liquefied specimens while the residual shear strain is created, the effects of the residual shear strain on residual volumetric strain could be directly evaluated. In addition, the tests were run in the lateral constrained condition closest to the actual soil by implementing the lateral constrain control throughout the processes of consolidation, cyclic loading, monotonic loading, and drainage. In level ground, the occurrence of lateral deformation is constrained (Ishihara, 1996). Second, based on the developed test method, an experimental approach was developed to investigate the core factors that influence residual strains during the post-liquefaction phase. Hence, a series of laboratory test programs were designed using relative density and accumulated shear strain as the test variables. Finally, the effects of the variables on residual deformation were examined. The internal variable of relative density was selected to represent the engineering characteristics of sand soil that resists liquefaction. The external variable of accumulated shear strain, which is an indicator that reflects the number of cycles, was selected to reflect the characteristics of earthquakes. 


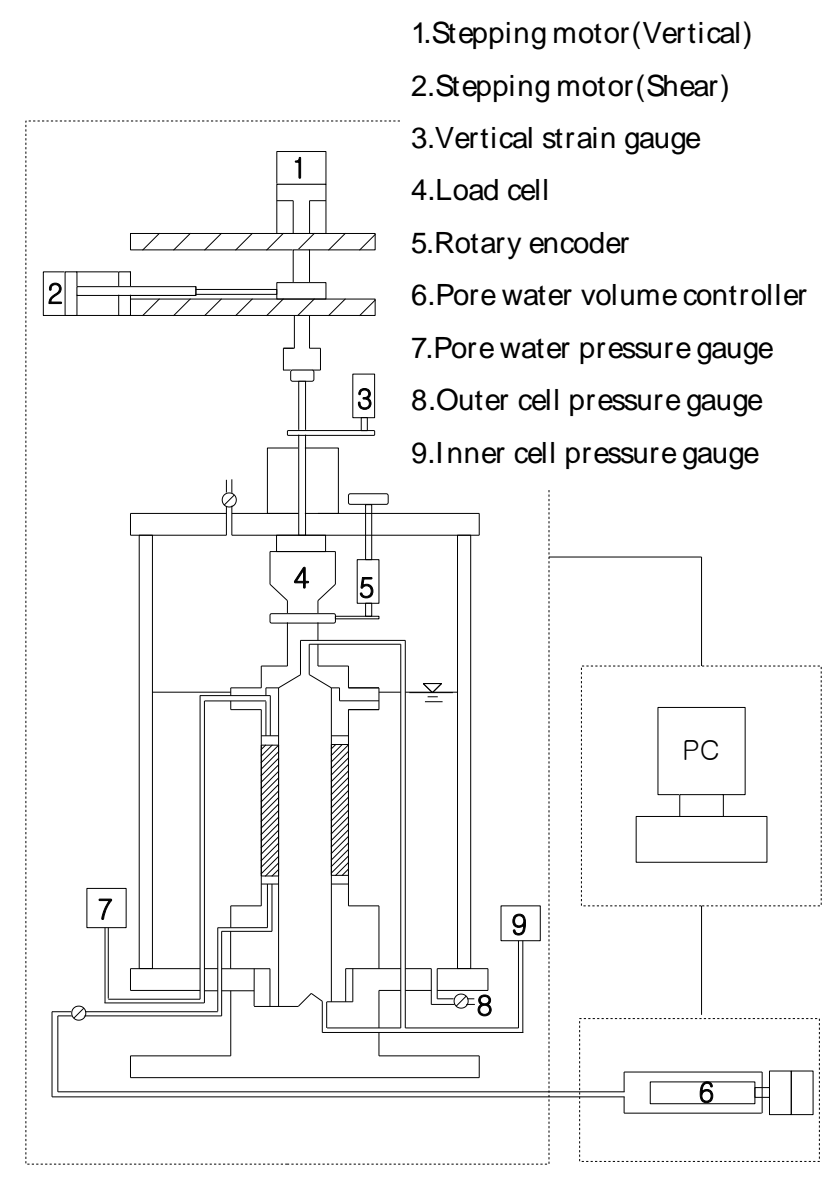

Fig. 1. Hollow cylindrical torsion testing apparatus.

\section{Description of testing details}

\subsection{Apparatus}

The test apparatus employed in the present study is shown in Fig. 1. The apparatus consists of a torsional shear experiment section, a pore-water volume controller (PWVC), and a personal computer (Fig. 1). Shear strain is applied using a stepping motor, and the shear strain resolution is $6.283 \times 10^{-6}$ radian pulse $^{-1}$. The PWVC regulates the discharge of pore water by controlling the horizontal movement of the piston ( $20 \mathrm{~mm}$ in diameter). The latter is included in the pore cell by the stepping motor and can precisely control the pore water pressure and amount of volume change. Based on the system's specifications, the resolution of PWVC can be calculated as $6.3 \times 10^{-5} \mathrm{cc}$ pulse $\mathrm{s}^{-1}$. A rotary encoder was adapted in this study to insure the accuracy of the shear strain. The rotary encoder counters the rotation angle of the specimen precisely without noise, resolving an angle of 360 degrees into 144000 pulses (Fig. 2).

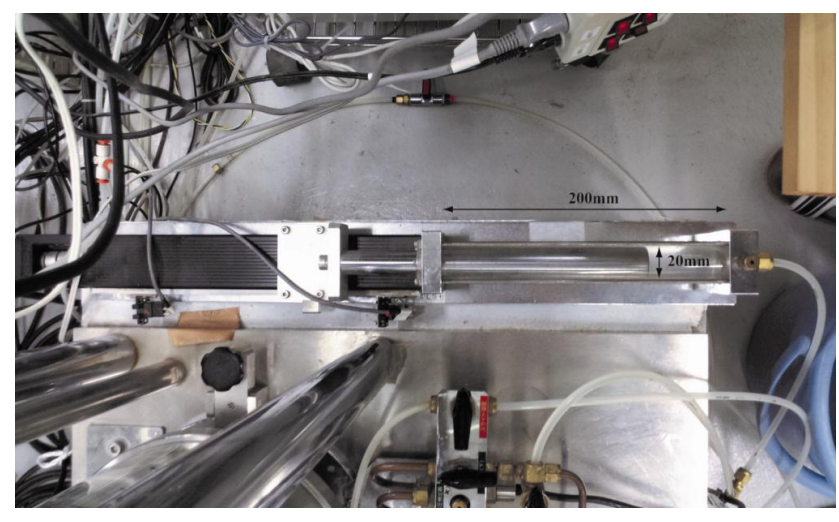

Fig. 2. Pore water volume controller.

Table 1. Test case of lateral constrain control method.

\begin{tabular}{lrrrr}
\hline Control method & $\sigma_{\mathrm{c}}^{\prime}(\mathrm{kPa})$ & $D_{\mathrm{r}}(\%)$ & $K_{0}$ & Cycle \\
\hline Lateral & 100 & 40 & 0.57 & 94 \\
Vertical & 100 & 41 & 0.59 & 125 \\
\hline
\end{tabular}

\subsection{Lateral constrain control method}

The lateral constrained condition was maintained during all the procedures in order to reproduce a level ground condition. Under this condition, no lateral or vertical strain was observed during the seismic excitation. Only vertical strain is generated with the dissipation of excess pore water pressure. It is well known that there are two methods to maintain the lateral constrained condition: vertical control, which alters the deviator stress to constrain the vertical strain, and lateral control, in which lateral pressure (cell pressure), instead of deviator stress, is varied.

To compare differences between the two lateral constrain control methods, a set of cyclic shear tests using a torsional shear test apparatus was carried out. The test case is shown in Table 1 . Note that $\sigma_{\mathrm{c}}^{\prime}, D_{\mathrm{r}}$ and $K_{0}$ are confining stress, relative density, and coefficient of lateral constrain, respectively. Figure 3 shows that the difference between different control methods is easily confirmed. In the case that lateral constrain was laterally controlled, a severe fluctuation of vertical strain, compared to that of vertical control, started around $12500 \mathrm{~s}$, at which point liquefaction occurred completely as shown in Fig. 3. Figure 3 shows the changes in normal vertical and lateral stress during the cyclic loading procedure. As the specimen is subjected to shear loading, lateral stress increases gradually. The coefficient of lateral confinement is almost 1 when liquefaction occurs. This result coincides with previous research (Ishihara et al., 1985). Figure 4 shows the results of cyclic loading and the subsequent monotonic loading. The reason for the stress recovery with lateral control is unclear, whereas with vertical control it might have occurred because 
Table 2. Soil properties.

\begin{tabular}{ll}
\hline Soil particle density $\rho_{d}\left(\mathrm{~g} \mathrm{~cm}^{3}\right)$ & 2.643 \\
Maximum void ratio $e_{\max }$ & 0.977 \\
Minimum void ratio $e_{\min }$ & 0.597 \\
$D_{50}$ & 0.17 \\
\hline
\end{tabular}

the drastic change in vertical strain might have functioned as another cyclic loading.

During the consolidation, cell pressure is increased slightly to create excess pore water pressure. The PWVC then dissipates the excess pore water pressure. The vertical stress is altered to regulate the generation of vertical strain to a permissible value, which is calculated by dividing the amount of drainage by the cross-sectional area. If the vertical stress is changed, lateral stress is also varied to produce constant, total stress. The procedure was repeated until the effective vertical stress became the initial effective vertical stress at $100 \mathrm{kPa}$. In addition, an anisotropic condition was employed using the $K_{0}$ consolidation procedure. During the drainage, the same procedure is carried out, except that cell pressure is not increased.

The assumption that no vertical and lateral strain would develop during cyclic loading was confirmed during cyclic and monotonic shear loading in the lateral constrain control process. The precise procedure for lateral constraint is almost the same as that of consolidation, but no drainage is allowed during cyclic and monotonic loading.

During pre-consolidation and drainage, vertical strain was controlled within an error of $5 \times 10^{-4} \mathrm{~cm}$. The error range was $1.0 \times 10^{-3} \mathrm{~cm}$ in the cyclic loading and monotonic loading procedures.

\subsection{Test procedures}

Toyoura sand was used to investigate residual strain characteristics in this study because it meets Japanese standards and its mineralogy is almost entirely quartz. Table 2 shows the specific properties of the sand.

A set of laterally constrained torsional tests under undrained conditions was run on samples to examine the residual deformation characteristics. The specimens were $7 \mathrm{~cm}$ in outer diameter, $3 \mathrm{~cm}$ in inner diameter, and $10 \mathrm{~cm}$ in height. They were prepared by pluviating dry sand through air, saturating it with circulating $\mathrm{CO}_{2}$ gas, percolating it through de-aired water, and then applying a backpressure of $98 \mathrm{kPa}$. The specimens' $B$ values were more than 0.95 in the test.

After pre-consolidation was completed, undrained torsional cyclic shear was conducted in a strain-controlled manner at a strain rate of $0.35 \% \mathrm{~min}^{-1}$. To investigate the residual strain characteristics, after cyclic loading a combination of monotonic loading and drainage was applied to the specimens. Three different test patterns were conducted, as
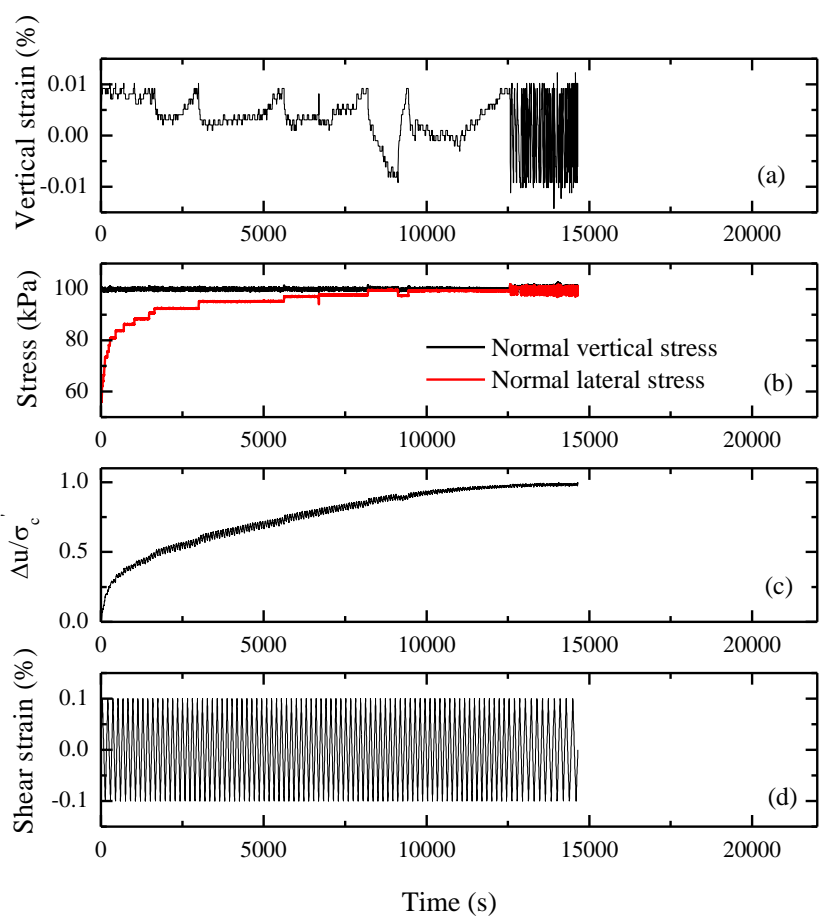

(a)
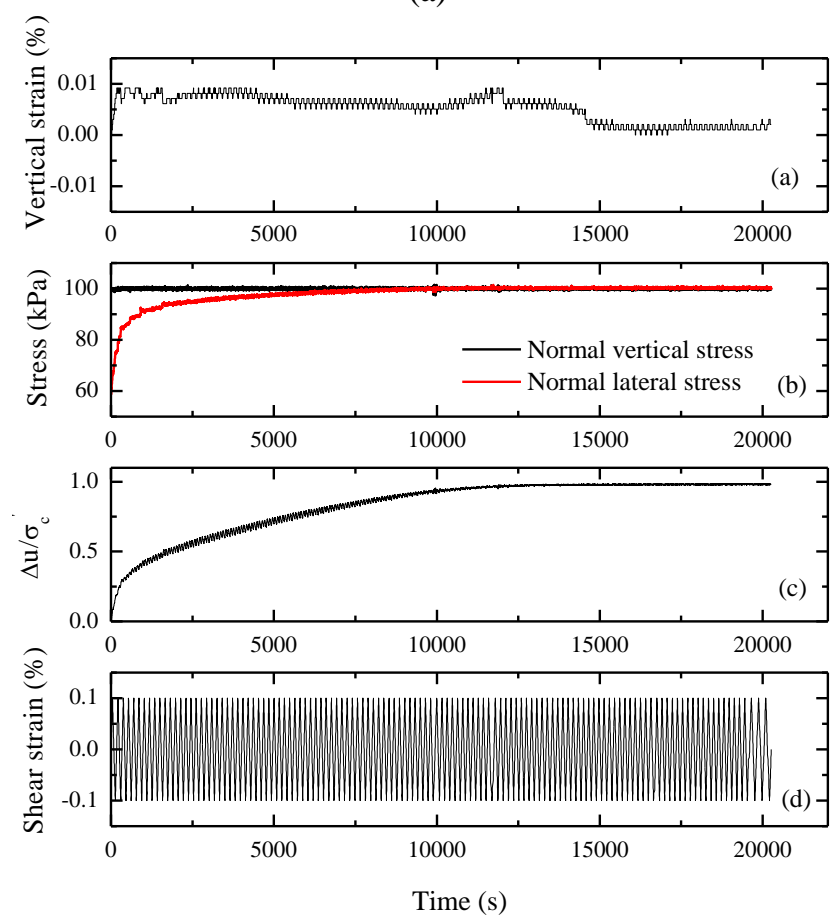

(b)

Fig. 3. Time history by two types of control; (a) laterally controlled case, and (b) vertically controlled case. 

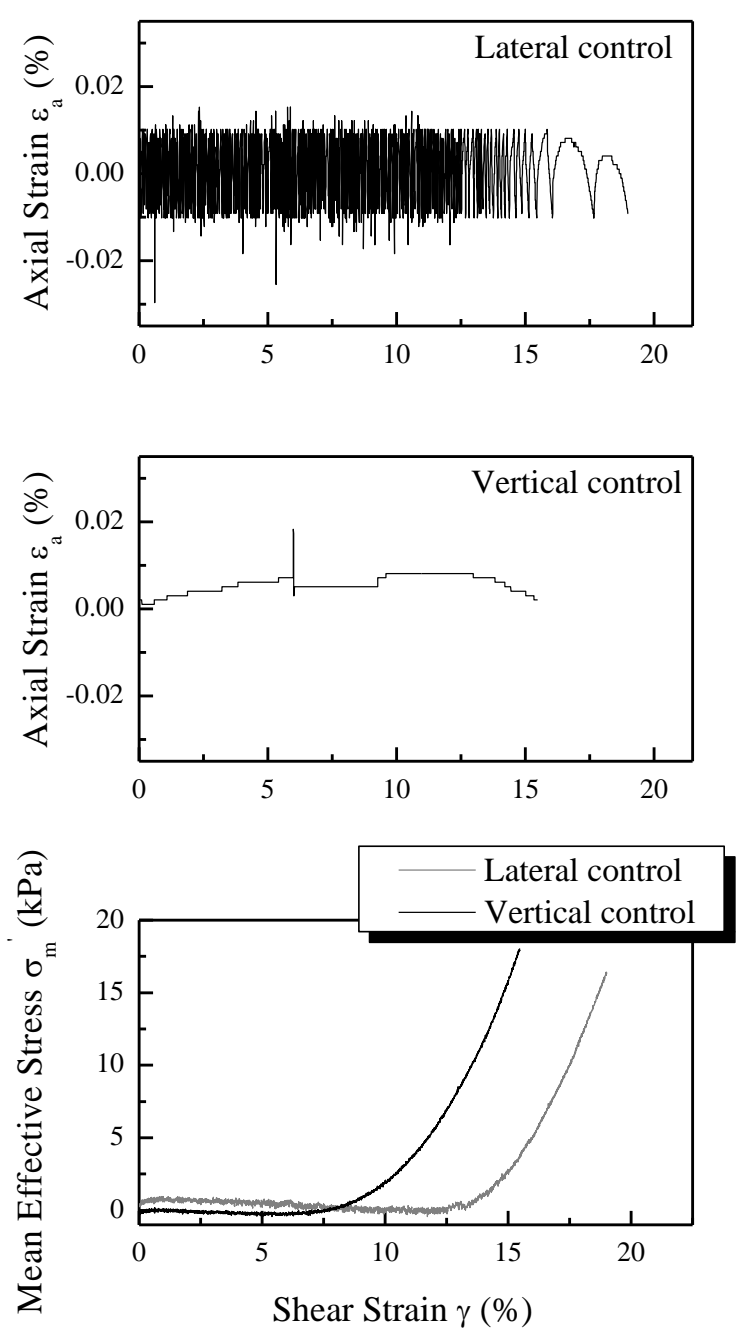

Fig. 4. Variation of axial strain and mean effective stress during monotonic loading.

shown in Fig. 5. The test procedure is described in detail below.

In pattern A, following the cyclic loading, drainage is conducted until the excess pore water pressure generated during cyclic loading is eliminated. This test method was adapted to examine the residual volumetric strain characteristics without the effect of residual shear. In contrast, to investigate the residual shear strain characteristics, monotonic loading is applied to the specimen after cyclic loading until the initial vertical effective stress is recovered, which is pattern C. In pattern $\mathrm{B}$, following the cyclic loading, monotonic loading is applied to the specimen to a strain level, and then drainage is conducted. In pattern B, it is possible to assess the residual volumetric strain concerning residual shear strain, that is, the relationship between residual volumetric strain and residual shear strain can be examined. As discussed in the introduction, this test pattern is studied most extensively.
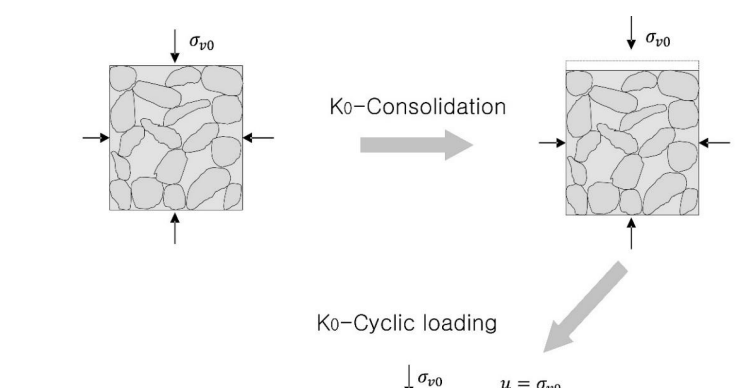

Ko-Cyclic loading
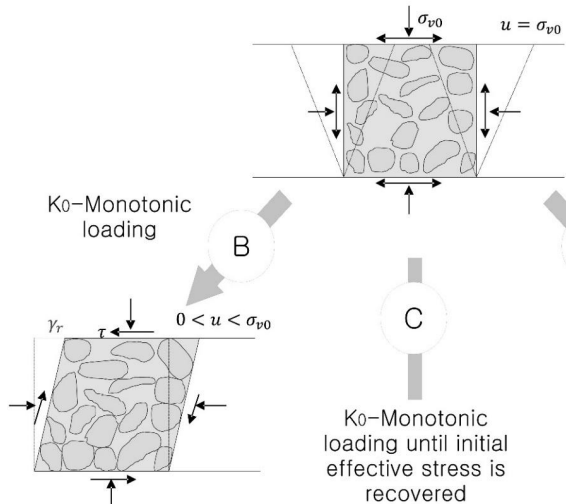

A

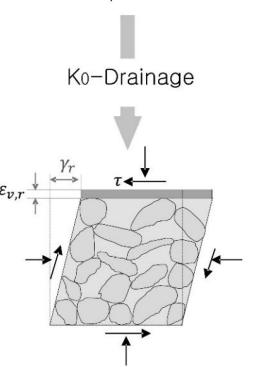
recovered

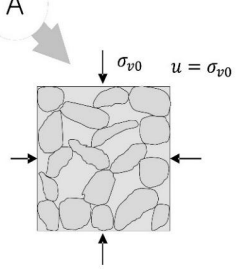

Fig. 5. Test procedure.

The maximum residual volumetric strain and maximum residual shear strain were obtained from pattern $\mathrm{A}$ and $\mathrm{C}$, respectively. The combination of residual shear strain and residual volumetric strain was attained by conducting pattern B. Figure 6 illustrates the entire testing procedure on the diagram showing specific volume $(1+e)$ vs. effective stress. The black rectangle and the black circles show the end point of the cyclic loading and each test pattern, respectively. The route for the end of the cyclic loading is indicated by the black rectangle. As the diagram shows, there is no difference between the test cases. After the cyclic loading is terminated, according to the test pattern, the route of specific volumeeffective stress is varied as shown in Fig. 6. In pattern A, the specific volume is decreased as the effective stress increases. In contrast, there is no change in specific volume in pattern $\mathrm{C}$ until the test ends because volume alteration has ceased. In pattern $\mathrm{B}$, the specific volume is not decreased during monotonic loading, somewhat as in pattern $\mathrm{C}$, and then it decreases as drainage occurs. 


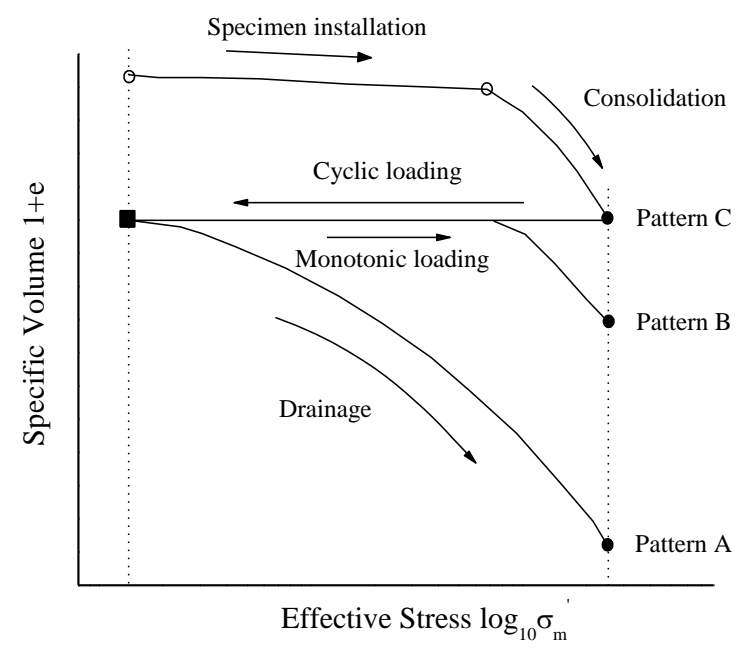

Fig. 6. Specific volume - effective stress diagram.

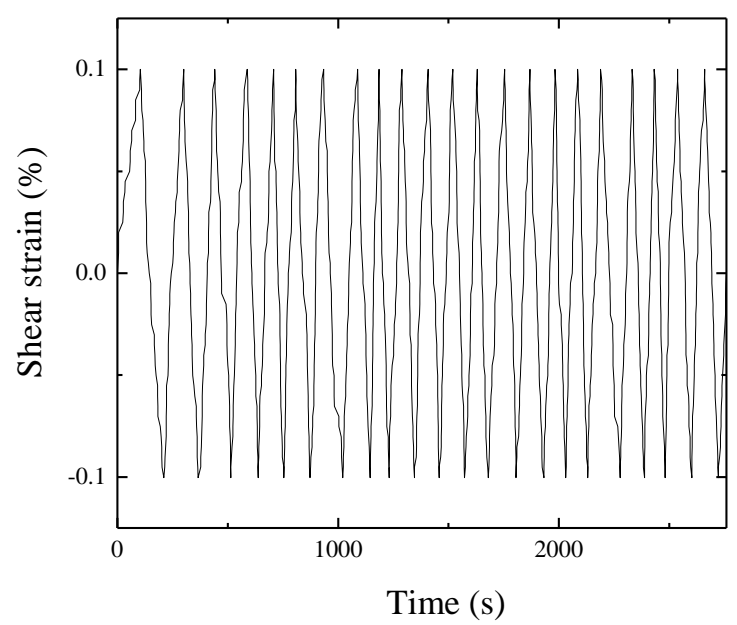

Fig. 7. Applied shear strain.

The test conditions adopted in this study are summarized in Table 2. In the present study, all cyclic loading was conducted by maintaining the specified single shear strain amplitude at $0.1 \%$ by using a computer that monitored the outputs from the rotary encoder. A time history of the shear strain applied in this study is shown in Fig. 7. The membrane force was corrected by referring to the method suggested by Pradhan (1989), which is based on elasticity theory, which employs Young's modulus of the membrane.

\section{Test results}

A brief summary of the test results is shown in Table 3 . The number of tests used in this paper is also summarized in Table 3. $K_{0 \mathrm{C}}$ and $K_{0 \mathrm{D}}$ are the coefficients of lateral confinement after consolidation and drainage, respectively. In the case of testing pattern C, $K_{0 \mathrm{D}}$ was obtained at the end of monotonic
Table 3. Summary of testing conditions.

\begin{tabular}{lrrrrrl}
\hline Pattern & $D_{\mathrm{r}}(\%)$ & $\sigma_{\mathrm{c}}^{\prime}(\mathrm{kPa})$ & $\gamma_{\text {acm }}$ & $\gamma_{\text {res }}(\%)$ & $B$ value & Test number \\
\hline B & 38 & 100 & 50 & 15 & 0.96 & B38_50 \\
B & 41 & 100 & 100 & 15 & 0.97 & B41_100 \\
C & 57 & 100 & 50 & 10.85 & 0.96 & C57_50 \\
B & 57 & 100 & 100 & 10.85 & 0.96 & B57_100 \\
A & 57 & 100 & 50 & 0 & 0.97 & A57_50 \\
B & 59 & 100 & 50 & 3 & 0.97 & B59_50 \\
\hline
\end{tabular}

Table 4. Brief summary of test results.

\begin{tabular}{lrrr}
\hline Case & $K_{0 C}$ & $K_{0 D}$ & $\varepsilon_{\mathrm{v}}(\%)$ \\
\hline B38_50 & 0.55 & 0.53 & 0.29 \\
B41_100 & 0.56 & 0.46 & 1.09 \\
C57_50 & 0.56 & 0.78 & 0 \\
B57_100 & 0.55 & 0.5 & 0.27 \\
A57_50 & 0.57 & 0.34 & 0.53 \\
B59_50 & 0.53 & 0.4 & 0.5 \\
\hline
\end{tabular}

loading stage; $\gamma_{\text {res }}(\%)$ is residual shear strain, and $\varepsilon_{\mathrm{V}}(\%)$ is residual volumetric strain.

\subsection{Variation of the coefficient of lateral confinement during $K_{0}$ consolidation}

The relationship between vertical effective stress and the coefficient of lateral confinement during $K_{0}$ consolidation is shown in Fig. 8. It was observed that the coefficient of lateral confinements during $K_{0}$ consolidation converged on almost the same value of 0.55 , independent of relative density. This tendency was caused by the consolidation method. In the present study, excess pore water pressure was generated by increasing the cell pressure during $K_{0}$ consolidation. Hence, excess pore water pressure built up as the cell pressure increased, which occurred regardless of relative density in the range of $40 \%$ to $60 \%$.

\subsection{Effect of relative density and accumulated shear strain during cyclic loading}

Normalized accumulated dissipation energy, $W / \sigma_{m 0}^{\prime}$, which was proposed to evaluate the ductility of soils (Kazama et al., 1999), and accumulated shear strain $\gamma_{\text {acm }}$ were employed as a hysteresis index during cyclic loading.

Dissipation energy refers to the energy dissipated into the soil of unit volume, that is, the present capacity of energy that soil can consume as plastic strain. Therefore, the dissipation energy in a cycle is equal to the area of a shear strain-shear stress loop, as shown in Fig. 9. Normalized accumulated dissipation energy was suggested as an index to evaluate the 


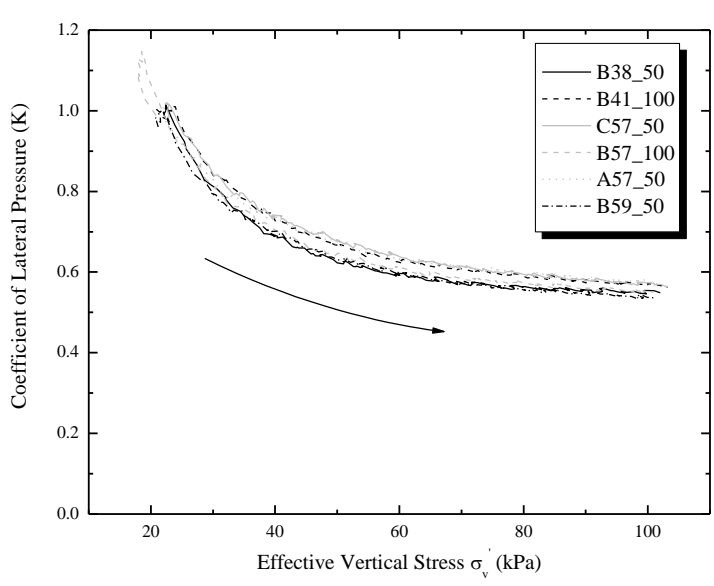

Fig. 8. Variation of $K$ value during $K_{0}$ consolidation.

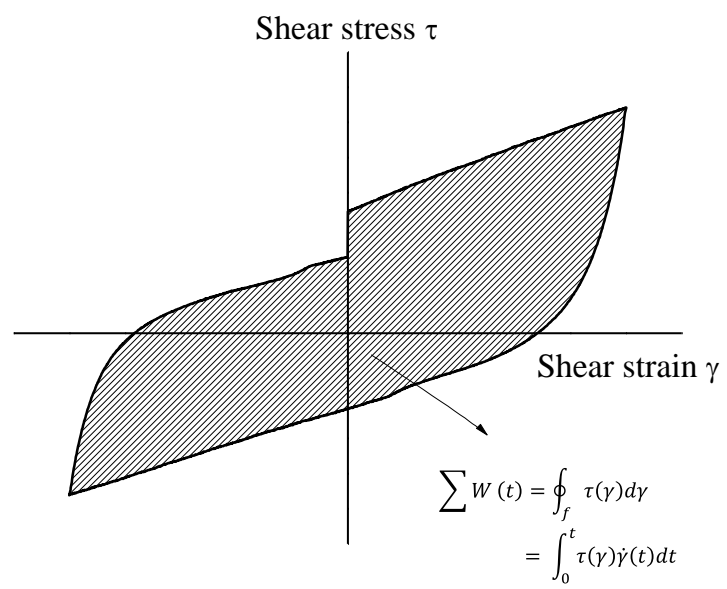

Fig. 9. Conceptual diagram of accumulated dissipation energy after Kazama et al., 1999).

general ductility of the liquefied soil, as follows:

$W / \sigma_{m 0}^{\prime}=1 / \sigma_{m 0}^{\prime} \cdot \int_{0}^{t} \tau(\gamma) \cdot \dot{\gamma}(t) \mathrm{d} t$,

where $\sigma_{m 0}^{\prime}, \tau(\gamma)$ and $\dot{\gamma}(\mathrm{t})$ ar e initial mean effective stress, shear stress, and rate of strain at time $t$. Accumulated shear strain is usually used to represent the damage to the soil for effective stress analysis. It can be determined as follows:

$\gamma_{\mathrm{acm}}=\int_{0}^{t}|\dot{\gamma}(t)| \mathrm{d} t$,

where $\dot{\gamma}(\mathrm{t})$ is the rate of shear strain at time $t$.

Figure 10 shows the changes in mean effective stress and excess pore water pressure during cyclic loading. As the relative density increases, the reduction of mean effective stress

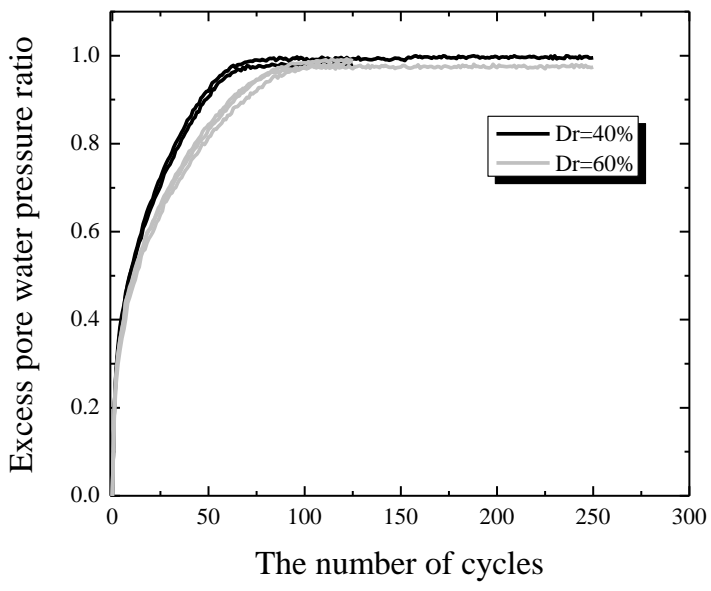

Fig. 10. Change of mean effective stress and excess pore water pressure with respect to the number of cycles.

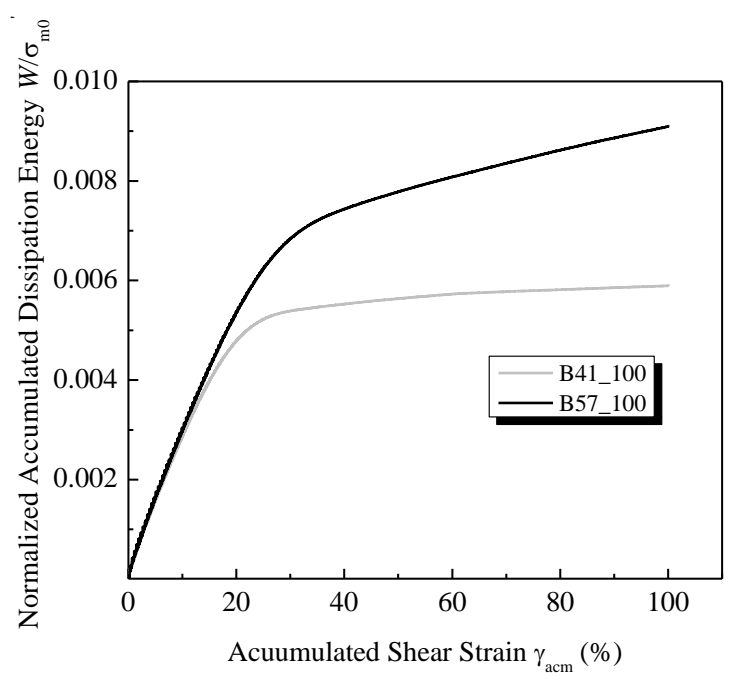

Fig. 11. Relationship between accumulated shear strain and normalized accumulated dissipation energy.

decreases, and the excess pore water pressure builds more slowly.

This tendency is explained in Fig. 11, which shows the normalized accumulated dissipation energy against the accumulated shear strain. It was observed that the rigidity of soil increases with relative density, which coincides with Yasuda et al. (1999). Figure 12 presents the pore water pressure variations, versus the normalized accumulated dissipation energy as determined by tests B41_100 and C57_50 in Kazama et al. (1999). Figure 12 also shows that in the range of $0-0.4$, pore pressure increased linearly, and over 0.4 , pore pressure slowly increased to almost 1.0. A decrease in the excess pore water pressure under higher relative density condition can be seen. Baziar and Sharafi (2011) and Jafarian et al. (2012) showed the same result. 


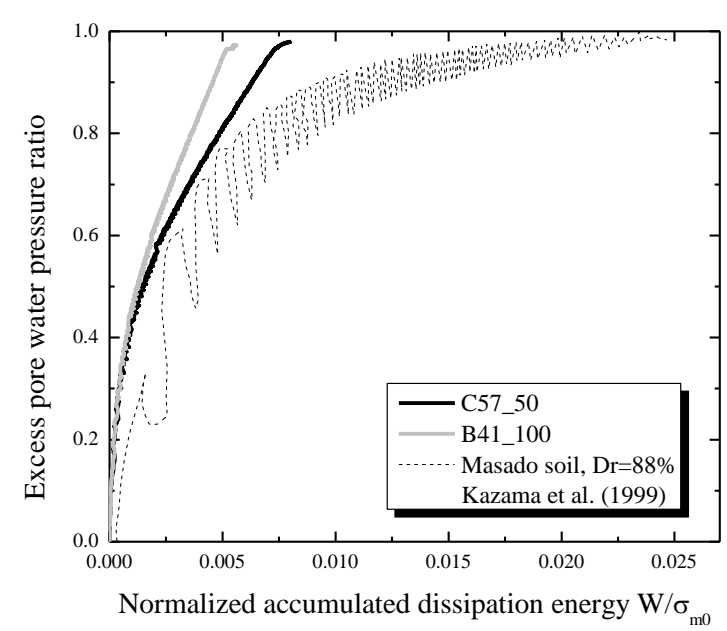

Fig. 12. Excess pore water pressure ratio against normalized accumulated dissipation energy during cyclic loading.

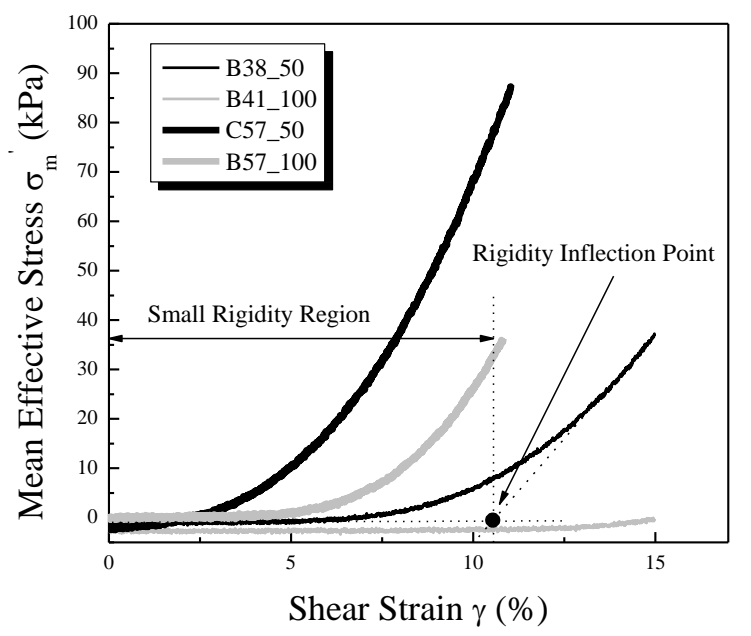

Fig. 13. Relationship between shear strain and mean effective stress during monotonic loading.

\subsection{Effect of relative density and accumulated shear strain during monotonic loading}

The stress-strain model proposed by Yasuda et al. (1999) was applied to determine the effect of relative density and accumulated shear strain during monotonic loading. When the specimen liquefied by cyclic loading was subjected to monotonic loading, an area called the small rigidity region, where shear strain increases sharply with extremely small shear stresses, can be identified. The stress-strain curve then develops a rigidity inflection point at which the slope rises and rigidity starts to recover.

The results during monotonic loading are plotted in Fig. 13, which shows the relationship between accumulated shear strain and mean effective stress. It was observed that when the relative density was $60 \%$, effective stress was recovered with less shear strain than when the relative density was $40 \%$. In the case of B41_100, effective stress was not recovered until $13 \%$ of shear strain was reached; at that point, the stress began to recover slightly. The small rigidity region became wider as the accumulated shear strain increased. Stress recovery was slow at the same relative density. Although in the case of B41_100, there was almost no recovery, it can be considered that the effect of accumulated shear strain is greater when the relative density is low. The small rigidity region was smaller in the case of B57_100 compared to the case of B38_50, which indicated that the effect of relative density on stress restoration during monotonic loading predominated over that of the accumulated shear strain, in the ranges of $D r=40-60 \%$ and $\gamma_{\text {acm }}=50-100 \%$, respectively. The results showed that even slight ground improvement and an increase in density might be effective as a countermeasure for the generation of residual shear strain.

\subsection{Variations in void ratio during the testing procedure}

The void ratios changed during the steps of the testing procedure. The variations in void ratios, including during consolidation, cyclic loading, monotonic loading, and drainage, in cases B38_50 and C57_50 are shown in Fig. 14. The results for case B38_50 showed that an effective stress increase was accompanied by a decrease in void ratio during consolidation. The effective stress then decreased with a constant void ratio during undrained cyclic loading. When monotonic loading was applied, the point of effective stress in Fig. 14 moved to the right side because of stress recovery without any changes in volumetric strain. Then the effective stress recovers its initial values by drain process, and as a result, it leads to a decrease in void ratio. However, in test B57_50 a different process was conducted after cyclic loading; no drainage occurred because the initial effective stress was restored by monotonic loading. Moreover, the mean effective stress at the end of monotonic loading was greater than that of the initial state. In this test, when the drainage was terminated, the vertical effective stress regained the initial state. However, it did not regain the mean effective stress because of the constant total vertical stress control. Thus, the mean effective stress at the end of the test varied according to the test method. This behavior may be regarded as the influence of fabric recovery, which is characteristic of liquefied soil. This feature can be explained by the observation that a difference in the coefficient of lateral confinement was found among the different test procedures when all procedures were finished. The specimen that recovered the initial vertical effective stress during drainage, without monotonic loading, exhibited high anisotropy, which might have resulted from predominant vertical contact among soil particles. In contrast, when the initial vertical effective stress recovered during monotonic loading, as the soil particle fabric was developed by dilatancy, the anisotropy was reduced. This anisotropic 


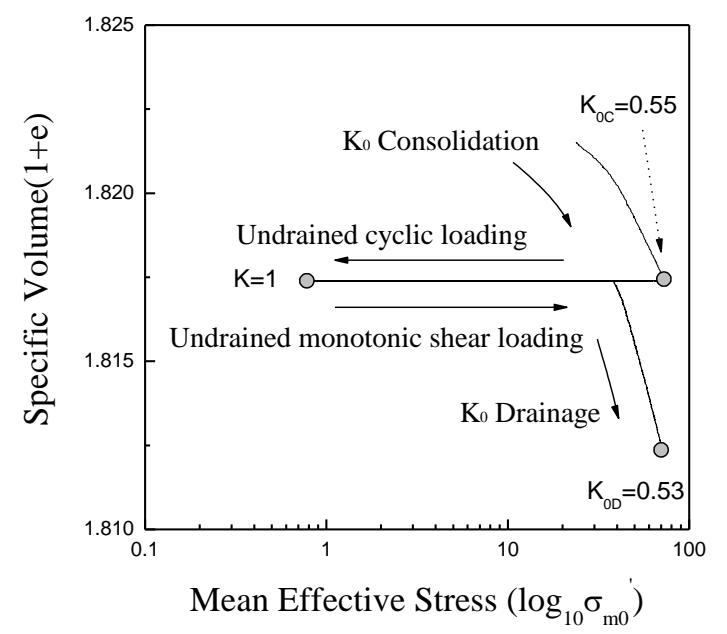

(a)

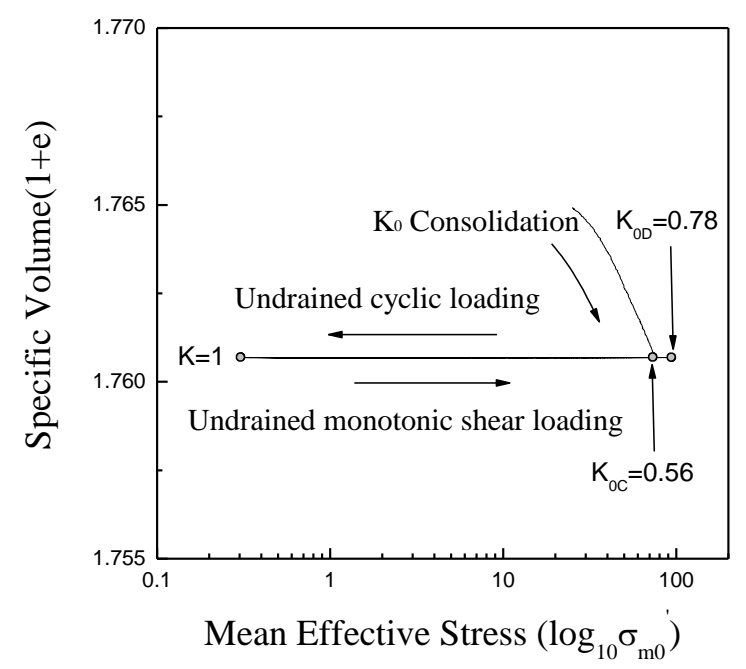

(b)

Fig. 14. Relationship between specific volume and mean effective stress during the test: (a) B38_50 and (b) C57_50.

tendency can be confirmed in Fig. 15, which shows stress recovery during monotonic loading and drainage of B38_50 and C57_50. The figure shows that stress recovery characteristics of monotonic loading and drainage are different from those in Fig. 15a. During monotonic loading, the stress recovery curve is similar in all stress directions, but during drainage, radial and circumference direction stress recovery slowed compare to that in the monotonic loading procedure.

\subsection{Residual strain characteristics}

Figure 16 shows the test results corresponding to the relationship between residual shear strain and residual volumetric strain. Each plotted point is a result of each test case. The relative density of $60 \%$ and accumulated shear strain of $50 \%$

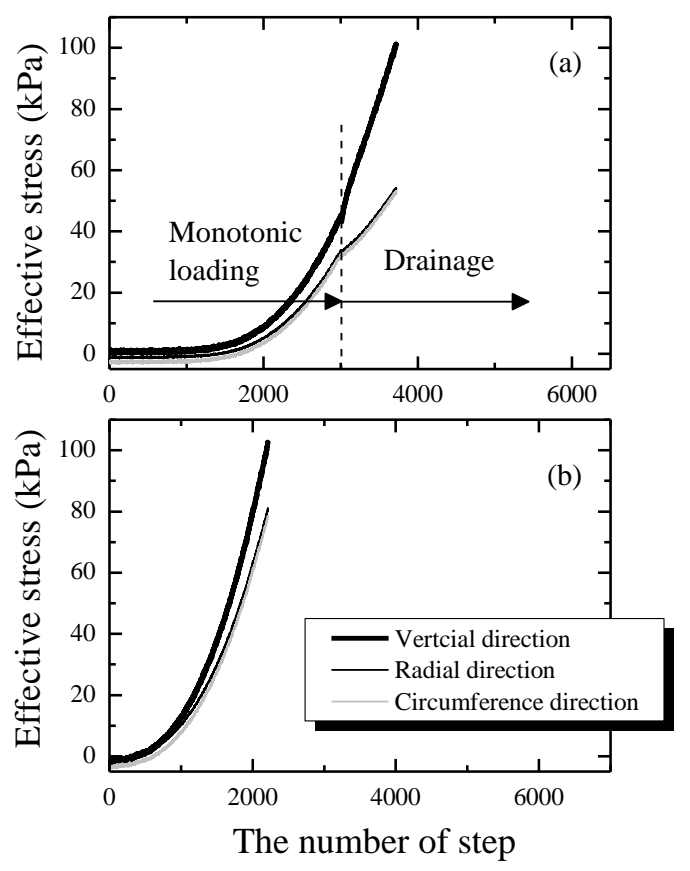

Fig. 15. Stress recovery during (a) monotonic loading and drainage of B38_50; (b) monotonic loading of C57_50.

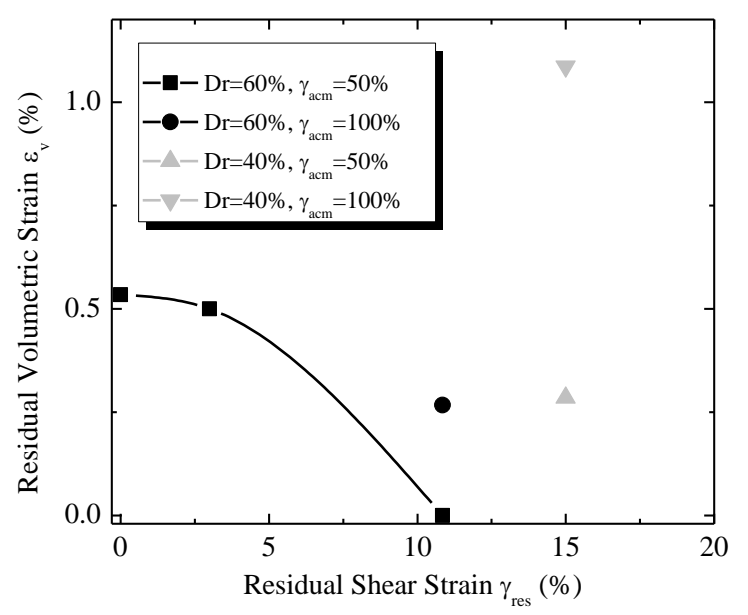

Fig. 16. Relationship between residual shear strain and residual volumetric strain.

(C57_50, A57_50, and B59_50) are connected by a line. The line shows that in the same ground and under the same external loading conditions, residual shear strain and residual volumetric strain have a unique relationship. Furthermore, the results showed the mutual effects of residual shear strain and residual volumetric strain. Thus, if the relationship between residual shear strain and residual volumetric strain is examined under various conditions, it is possible to assess the post-liquefaction damage quantitatively. Although 
this inverse correlation coincides with that of Shamoto et al. (1998) who showed linear inverse correlation between residual shear strain and residual volumetric strain, the result in this study shows curvilinear relationship, not linear.

Residual volumetric strain increases with accumulated shear strain at a constant relative density and residual shear strain. The results showed almost the same residual volumetric strain in case B38_50 and case B57_100; however, residual shear strain differs between the relative densities of $40 \%$ and $60 \%$. Thus, it can be confirmed that if the residual shear strains in cases B38_50 and B57_100 are equal, then the volumetric strain of case B38_50 would be greater than that of case B57_100.

Residual shear strain and residual volumetric strain are related by the characteristic of dilatancy and thus are not independent (Oshima et al., 2008). The relationship, called residual strain potential, can be expressed as follows:

$\varepsilon=\sqrt{\varepsilon_{\mathrm{v}}^{2}+\left(\gamma_{\mathrm{res}} \cdot D\right)^{2}}$,

where $\varepsilon_{\mathrm{v}}, \varepsilon_{\text {res }}$, and $D$ are residual volumetric strain, residual shear strain, and dilatancy coefficient (the ratio of increment of residual shear strain and residual volumetric strain), respectively. The $\varepsilon$ expresses the potential of residual strain, which will be generated during an earthquake in some ground conditions. By conducting further tests under a variety of conditions, residual strain can be estimated quantitatively for some ground conditions and earthquake scales. The $D$ value determined in the present study was 0.05 . The relationship between accumulated shear strain and residual strain potential is shown in Fig. 17. As relative density decreases, the residual strain potential increases, and the impact of accumulated shear strain is greater. It is expected that the dilatancy coefficient $D$ would vary with the alteration of relative density, accumulated shear strain, and diverse parameters. Thus, further investigation of the variation characteristics of the dilatancy coefficient is recommended.

\section{Conclusions}

As the first step in the quantitative estimation of residual strain after liquefaction, a test procedure that examined the relationship between residual shear strain and residual volumetric strain was proposed. In the test procedure, a series of undrained torsional shear tests consisting of consolidation, cyclic loading, monotonic loading, and drainage was conducted while maintaining lateral constrained condition to examine the effects of relative density and accumulated shear strain on residual strain characteristics. The test results are summarized as follows:

1. Using the suggested test method, the relationship between residual shear strain and residual volumetric strain, as well as the quantitative estimation of residual strain, were confirmed.

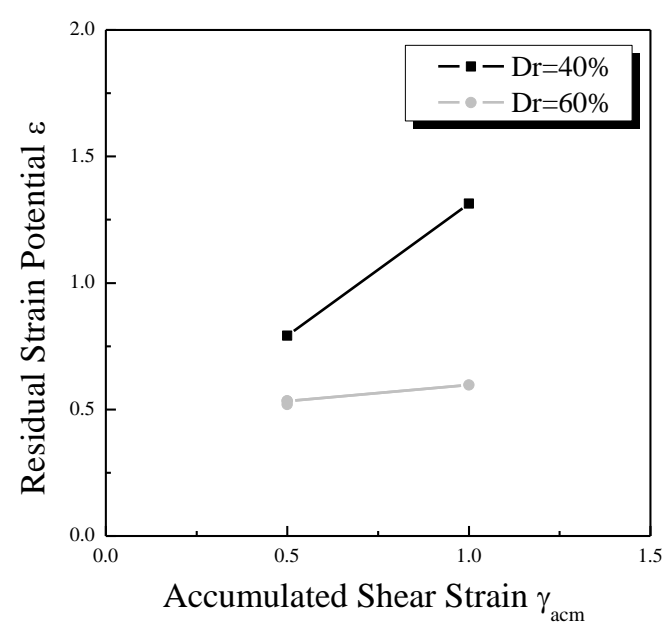

Fig. 17. Relationship between accumulated shear strain and residual strain potential.

2. During cyclic loading, the small rigidity region becomes wider with increasing accumulated shear strain and decreasing relative density. It is affected by relative density more than by accumulated shear strain in the ranges of $D r=40-60 \%$ and $\gamma_{\mathrm{acm}}=50-100 \%$, respectively.

3. Comparison of the residual volumetric strain at identical residual shear strain and relative density revealed that the greater accumulated shear strain, the more residual volumetric strains were induced.

4. The dilatancy characteristics of the soil affect effective stress recovery behavior in the processes of monotonic loading and drainage. The specimen that recovered initial vertical effective stress during drainage, without monotonic loading, exhibited high anisotropy, which might have been caused by predominant vertical contact among the soil particles. In contrast, when the initial vertical effective stress recovered during monotonic loading, the anisotropy was reduced because the soil particle fabric is developed by dilatancy.

5. Residual strain potential may be used as the potential index for damage after liquefaction. Furthermore, when accumulated shear strain is adapted as an index for external loading, residual strain potential also increases as accumulated shear strain rise high.

Acknowledgements. This research was supported by Basic Science Research Program through the National Research Foundation of Korea (NRF) funded by the Ministry of Science, ICT \& Future Planning (2012R1A1A1010173).

Edited by: D. Keefer

Reviewed by: R. Moss and two anonymous referees 


\section{References}

Baziar, M. H. and Sharafi, H.: Assessment of silty sand liquefaction potential using hollow torsional tests-An energy approach, Soil Dynam. Earthq. Eng., 31, 857-865, 2011.

Cubrinovski, M., Bray, J. D., Taylor, M., Giorgini, S., Bradley, B., Wotherspoon, L., and Zupan, J.: Soil Liquefaction effects in the central business district during the February 2011 Christchurch Earthquake, Seismol. Res. Lett., 82, 893-904, 2011.

Hatanaka, M. and Yokoji, S.: Post earthquake strain of cohesive soils due to undrained cyclic loading, Taylor Francis Group, London, ISBN 978-0-415-5564-9, 2009.

Hatanaka, M., Uchida, A., and Ohara, J.: Liquefaction characteristics of a gravelly fill liquefied during the 1995 Hyogo-Ken Nanbu earthquake, Soils Foundations, 37, 107-115, 1997.

Hyodo, M., Kim, J., Fukumoto, K., Yamada, S., and Yoshimoto, N.: Undrained cyclic behavior of sand and clay mixture subjected to initial static shear stress, J. JSCE, Division C, 62, 240-245, 2006.

Ishihara, K.: Liquefaction and flow failure during earthquake, Geotechnique, 43, 351-415, 1993.

Ishihara, K.: Soils behavior in earthquake geotechnics, Oxford Eng. Sience series, 46, 231-233, 1996.

Ishihara, K. and Yoshimine, M.: Evaluation of settlements in sand deposits following liquefaction during earthquakes, Soils Foundations, 32, 173-188, 1992.

Ishihara, K., Yamazaki, A., and Haga, K.: Liquefaction of $\mathrm{K}_{0^{-}}$ consolidated sand under rotation of principal stress direction with lateral constraint, Soils Foundations, 25, 63-74, 1985.

Ishihara, K., Yasuda, S., and Nagase, H.: Soil characteristics and ground damage, Soils and Foundations, Special Issue on geotechnical aspects of the January 171995 Hyogoken-Nambu earthquakes, 109-118, 1996.

Jafarian, Y., Towhata, I., Baziar, M. H., Noorzad, A., and Bahmanpour, A.: Strain energy based evaluation of liquefaction and residual pore water pressure in sands using cyclic torsional shear experiments, Soil Dynam. Earthq. Eng., 35, 13-28, 2012.

Kaggawa, W. S., Booker, J. R., and Cater, J. P.: Residual strains in calcareous sand due to irregular cyclic loading, J. Geotech. Eng. ASCE, 117, 201-218, 1991.

Kato, S., Ishihara, K., and Towhata, I.: Undrained shear characteristics of saturated sand under anisotropic consolidation, Soils Foundations, 41, 1-11, 2001.

Kawakami, F. and Asada. F.: Damage to the ground and earth structures by the Niigata earthquake of June 16, 1964, Soils Foundations, 6, 14-30, 1966.

Kazama, M., Suzuki, T., and Yanagisawa, E.: Evaluation of dissipation energy accumulated in surface ground and its application to liquefaction prediction, Proceedings of JSCE, 631, 161-177, 1999.

Lee, K. L. and Albaisa, A.: Earthquake induced settlements in saturated sands, J. Geotech. Engrg. Division, ASCE, 100, 387-406, 1974.

Nagase, H. and Ishihara, K.: Liquefaction-induced compaction and settlement of sand during earthquake, Soils Foundations, 28, 65$76,1988$.
Oshima, T., Kazama, M., Sento, N., Kawamura, K., and Hayashi, K.: Evaluation of liquefaction resistance and deformation characteristic after cyclic shear loading of improved sand by permeable grouting method, J. JSCE, Division C, 64, 732-745, 2008.

Pendo, M. D., Jonathan, P. S., Daniel, H. W. and Eric, Y.: Volumetric strains of clean sand subject to cyclic loads, J. Geotech. Geoenvion. Eng., 134, 1073-1085, 2008.

Pradhan, T. B. S.: The behavior of sand subjected to monotonic and cyclic loadings, A dissertation submitted for the doctor of engineering at the graduate school of civil engineering, Kyoto university, 1989.

Seed, H. B. and Idriss, I. M.: Simplified procedure for evaluating soil liquefaction potential, J. Soil. Mech. Foundations Division, ASCE, 97, 1249-1273, 1971.

Sento, N., Kazama, M., and Uzuoka, R.: Experiment and idealization of the volumetric compression characteristics of clean sand after undrained cyclic shear, J. JSCE, 67, 307-317, 2004.

Shamoto, Y., Zhang, J.-M., and Goto, S.: Mechanism of large postliquefaction deformation in saturated sand, Soils Foundations, 37, 71-80, 1997.

Shamoto, Y., Zhang, J. M., and Tokimatsu, K.: New charts for predicting large residual post-liquefaction ground deformation, Soil Dynam. Earthq. Eng., 17, 724-438, 1998.

Shamoto, Y., Sato, M., and Zhang, J.-M.: Simplified estimation of earthquake-induced settlements in saturated sand deposits, Soils Foundations, 36, 39-50, 1996.

Takahashi, H., Yoshida, J., Sento, N., Mori, T., Uzuoka, R., and Kazama M.: Evaluation of residual deformation after earthquake by means of $\mathrm{K}_{0}$ on-line seismic response experiment, J. JSCE, Division C, 68, 274-285, 2012.

Tatsuoka, F., Sasaki, T., and Yamada, S.: Settlement in saturated sand induced by cyclic undrained simple shear, Proc. 8th World Conf. on Earthquake Engrg., 3, 398-405, 1984.

Tetsuro, I. and Koarai, M.: Wide-area land subsidence caused by "the 2011 off the Pacific Coast of Tohoku Earthquake", Soils Foundations, 52, 842-855, 2012.

Tokimatsu, K. and Seed, H. B.: Evaluation of settlements in sands due to earthquake shaking, J. Geotech. Engrg. Division, ASCE, 113, 861-878, 1987.

Unno, T. and Tani, S.: The effect of test control and test condition on the assessment of volume compressibility following liquefaction based on the cyclic shear strain histories, J. JSCE, 64, 776-781, 2008.

Unno, T., Kazama, M., Uzuoka, R., and Sento, N.: Relation of volumetric compression of sand between under drained cyclic shear and reconsolidation after undrained cyclic shear, J. JSCE, 62, 757-766, 2006.

Wang, Y. and Wang, Y.: The effects of fines on post liquefaction strength and deformation characteristics of sand, Adv. Materials Res., 594-597, 23-27, 2012.

Yasuda, S., Yoshida, N., Adachi, K., Kiku, H., Gose, S., and Masuda, T.: A simplified practical method for evaluating liquefaction-induced flow, Proc. JSCE, 638, 71-89, 1999.

Yoshimi, Y., Kuwabara, F., and Tokimatsu, K.: One-dimension volume change characteristics of sands under very low confining stress, Soils Foundations, 15, 51-60, 1975. 